\title{
EL PEDIATRA Y LOS CAMBIOS DE POBLACIÓN EN AMÉRICA LATINA*
}

\author{
JoÃo YUNES ** \\ Centro de Estudios de Dinámica de la Población (CEDIP)
}

El CREcimiento de la población en el mundo actual es sin duda uno de los temas de mayor debate, y existe gran controversia acerca de las consecuencias de este crecimiento.

Cuando se discuten decisiones importantes que involucran políticas de población, tanto en países desarrollados como de escaso desarrollo relativo, es necesario poner empeño en estudios, análisis e investigaciones científicas, que eviten los prejuicios y los arrebatos emocionales que con tanta frecuencia se imponen en tales controversias. Las tesis pronatalistas y controlistas se oponen una a la otra sin considerar otros factores tales como la densidad demográfica, los recursos naturales, tendencias de la tasa de natalidad, el proceso de urbanización, esto es, los factores demográficos, económicos, sociales y culturales que determinan la conveniencia de decisiones políticas concretas, las que a su vez constituyen una de las más agudas controversias de nuestra época [19].

\section{Políticas de Población}

Patrocinados con ayuda oficial de sus propios gobiernos, o de organismos privados, en 1969 existían programas de planeación familiar en 16 países de América Latina distribuidos como sigue:

Sudamérica: Colombia, Ecuador y Guyana.

Centroamérica: Costa Rica, El Salvador, Guatemala, Honduras, Nicaragua y Panamá.

Caribe: Barbados, Cuba, Haití, Jamaica, República Dominicana y Trinidad-Tobago.

* La versión en inglés de este trabajo se presentó en una reunión previa del XIV Congreso Internacional de Pediatría, celebrado en Buenos Aires, en octubre de 1974 por invitación de la Asociación Internacional de Pediatría (AIP). La traducción es de Roberto Ham Chande.

** Este trabajo se realizó durante la estancia del autor en el CEDIP (C. P. 8099, São Paulo, Brasil) y en el Departamento de Pediatría de la Universidad de São Paulo. 
En seis países latinoamericanos hay centros de planeación familiar administrados por la iniciativa privada, algunos con ayuda gubernamental importante al grado de permitirles utilizar edificios pertenecientes a la Universidad o al Estado: Argentina, Brasil, Paraguay, Venezuela, Uruguay y México.

En otros dos países, Perú y Bolivia, la planeación familiar no recibe ayuda oficial y sus actividades son limitadas.

En algunos países la política del gobierno está en contra de la planeación familiar, aunque de manera paradójica existen acciones bien des-

\section{Cuadro 1}

AmÉrica Latina: Política del gobierno sobre el CRecimiento * DE LA POBLACIÓN Y ACTIVIDADES DE PLANEACIÓN FAMILIAR, 1972

\begin{tabular}{|c|c|c|c|}
\hline Paris & $\begin{array}{c}\text { Poblao162 } \\
1971\end{array}$ & $\begin{array}{l}\text { Polftioa b/ } \\
\text { ael soblerno }\end{array}$ & $\begin{array}{l}\text { Año on gae } \\
\text { lniciaron } \\
\text { programas }\end{array}$ \\
\hline 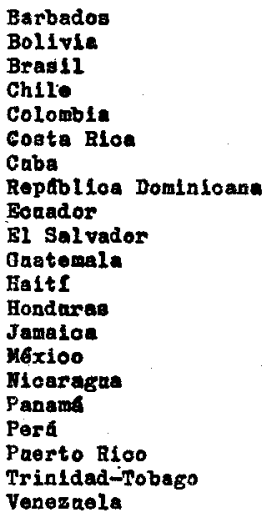 & $\begin{array}{r}0.26 \\
5.1 \\
98.0 \\
10.0 \\
23.0 \\
1.8 \\
8.5 \\
4.5 \\
6.3 \\
3.6 \\
5.4 \\
5.0 \\
2.7 \\
2.1 \\
51.0 \\
2.0 \\
1.5 \\
14.0 \\
2.9 \\
1.0 \\
10.8\end{array}$ & $\begin{array}{l}A \\
B \\
C \\
B \\
A \\
B \\
B \\
A \\
A \\
B \\
B \\
B \\
B \\
B \\
A \\
C \\
B \\
B \\
C \\
A \\
A \\
B\end{array}$ & $\begin{array}{l}1967 \\
1969 \\
1965 \\
1970 \\
1968 \\
19600 \\
1968 \\
1968 \\
1968 \\
1969 \\
1971 \\
1960 \\
1966 \\
1967 \\
1969 \\
1970 \\
1970 \\
1968\end{array}$ \\
\hline
\end{tabular}

Fuente: Population Council, "Reportes sobre población: Planeación familiar", Núm. 2, 4a edición, septiembre de 1972.

a Millones de habitantes.

b $A$ : Política oficial para reducir la tasa de crecimiento de la población. Los países en esta categoría auspician programas de planificación familiar tanto para habilitar dicha política como por razones de salud y de derechos humanos; $B$ : Apoyo oficial a actividades de planeación familiar por razones no demográficas. Los países en esta categoría apoyan programas de planificación familiar por razones de salud o de derechos humanos, pero cualquier efecto antinatalista es un subproducto, no un objetivo; $C$ : Categoría residual. Los países de este grupo ni tienen una política para reducir la tasa de crecimiento de la población, ni auspician programas de planeación familiar por ninguna razón, sea o no demográfica. Por lo tanto, la lista incluye países que son neutrales en cuanto a su tasa de crecimiento de la población como a los pronatalistas, pero la distinción entre "neutral" y "pronatalista" es de carácter conjetural y no garantiza una clasificación en categorías separadas.

c A principios de los años sesentas. 
arrolladas que involucran planeación familiar. Hay tres países en tal situción: Brasil, Uruguay y Argentina.

Como se observa en el cuadro 1 , en 1971 se dio ayuda oficial en 18 países, y en seis de éstos el gobierno se pronunció por una política de reducción del crecimiento de la población. En los restantes 12 se dio ayuda oficial aludiendo razones distintas a las demográficas. Para ese año la población estimada para América Latina era de 265 millones de habitantes, de los cuales 96 millones se veían afectados por la política oficial o ayuda gubernamental.

El acelerado crecimiento demográfico de los países latinoamericanos (que implica una gran reducción de la mortalidad más que de la tasa de mortalidad, la cual aún permanece a niveles generales muy altos) ha suscitado una fuerte controversia, especialmente en lo que se refiere a sus conveniencias económicas.

Un grupo de economistas sostiene que una política tendiente a reducir el crecimiento de la población tendría un efecto benéfico en el desarrollo económico y social de la mayoría de los países latinoamericanos [17]. Un economista brasileño [3] ha declarado asimismo que el rápido crecimiento de la población es una de las razones por las cuales Brasil se enfrenta a enormes problemas de desempleo, educación y desarrollo económico. Aunque podemos decir que la tasa de natalidad no ha descendido sensiblemente en los países que han adoptado como politica el control de la población.

¿No se relaciona el descenso de la fertilidad con el desarrollo social y económico, tal y como lo hemos observado en los países desarrollados después de su revolución industrial? ¿Es la acelerada "explosión demográfica" una verdadera causa del subdesarrollo? ¿Es esta "explosión demográfica" una enfermedad que requiere un tratamiento médico de urgencia, o es una crisis social que requiere de medidas de distinta naturaleza y punto de vista?

El problema demográfico es distinto para cada país, y las generalizaciones que es costumbre hacer no necesariamente se adaptan al caso brasileño, ni a la mayoría de las demás naciones. Respecto a la importante y controvertida cuestión de las relaciones entre tamaño de la población, tasa de crecimiento y desarrollo económico, se deben estudiar en cada caso particular las condiciones reales de las relaciones entre recursos naturales y población, y la capacidad del proceso de desarrollo para absorber trabajadores en cada sistema económico. Las relaciones entre desarrollo económico y población, al igual que los motivos económicos, sociales y culturales que tienden a condicionar diferentes tasas de fertilidad son de naturaleza muy compleja y merecen estudios adicionales.

Lo que no podemos aceptar sin inquietud, es la manera en que muchos autores neomalthusianos reducen el desarrollo económico al crecimiento del ingreso per capita, y atribuir al reparto del producto nacional entre más gente, a medida que nacen nuevos individuos, la causa del atraso social y del estancamiento económico. 
De acuerdo con Paulo Singer, economista y demógrafo brasileño, el tamaño, la estructura y el crecimiento de la población tienen un efecto doble en el funcionamiento de una economía: son los principales determinantes de la oferta de mano de obra, y al mismo tiempo, influyen grandemente en el consumo. Por lo tanto, los efectos de la dinámica de la población se dejan sentir simultáneamente tanto del lado de la oferta como de la demanda de bienes y servicios. Sin lugar a dudas la población y su nivel de ingreso son los principales determinantes del tamaño del mercado; desde el punto de vista de las economías de escala, la población es el factor más importante, aunque la proposición de que el crecimiento demográfico acrecienta el mercado no puede ser totalmente generalizado, no obstante sigue siendo cierta para la mayoría de los países capaces de desarrollar su economía. Una mayor población significa un mayor mercado, y en consecuencia un mayor nivel de industrialización. Al contrario de la integración económica, el crecimiento de la población no depende de tratados firmados con otros países, debido a lo cual representa una "solución" más fácil de alcanzar para problema tan vital. Por ello se concluye que, excepto para algunas naciones de gran población, el crecimiento demográfico es un factor positivo; la medición del efecto del crecimiento poblacional en el desarrollo debe hacerse bajo las condiciones especiales en las que se encuentra cada país.

Angel Fucaraccio [7], economista del Centro Latinoamericano de Demografía, en un artículo presenta un análisis de la tesis antinatalista que utilizan como argumentos el ahorro y la inversión, y demuestra que es básicamente un problema ideológico, de modo que resulta un producto de reflexiones que no expresan la realidad de América Latina. Una de sus conclusiones principales es la de que el control de nacimientos se dirige hacia los pobres (ya que los ricos lo hacen voluntariamente) y no tienen efectos económicos ya que se ejerce y administra por las clases altas. Existe entonces una contradicción entre la idea de controlar la natalidad y una economía sólida debido a que el control se dirige a individuos sin poder económico, y la posibilidad de que lo obtengan es aún remota.

En el cuadro 2 se presenta el ingreso anual per capita en América Latina, comparado en el de algunos países desarrollados.

En Chile [13], los sindicatos de trabajadores se pronunciaron en favor de la planeación familiar siempre y cuando se tratara de un asunto de familia, aceptando la planeación familiar y rechazando el control de natalidad como solución del subdesarrollo de Latinoamérica.

El congreso de escuelas de salud pública en América Latina sobre salud y población (1970) [9], estableció, entre una de sus principales conclusiones, que incorporar actividades de planeación familiar dentro del sector salud implica, aun cuando el objetivo no fuera el control del crecimiento de la población y aunque no esté totalmente demostrado, que éstas pueden tener algún efecto restrictivo sobre la fecundidad. Hubo acuerdo general para aceptar la existencia de otros factores en el sector 
Cuadro 2

INGReso per capita ANUAL dE PAÍSES SELECcronados dE AMÉRICA LATINa Y ALGUNOS PAÍSES DESARROLLADOS

\begin{tabular}{ccc}
\hline Ingreso per capita & $\begin{array}{c}\text { Andrioa } \\
\text { Latina }\end{array}$ & $\begin{array}{c}\text { Algunos paises } \\
\text { desarrollados }\end{array}$ \\
\hline menos de 100 & 1 & 0 \\
$100=299$ & 8 & 0 \\
$300=499$ & 5 & 0 \\
$500=749$ & 3 & 0 \\
$750=999$ & 2 & 1 \\
$1000=1499$ & 0 & 4 \\
$1500=1999$ & 1 & 6 \\
$2000=0$ mas & 0 & 1 \\
no disponible & 1 & 12 \\
Total & 21 & \\
\hline
\end{tabular}

Fuente: Population Council, "Informe sobre población: Planificación familiar", Núm. 2, 4a edición, septiembre de 1972.

a En dólares (de 1968 o 1969).

salud como de mayor influencia. Por otra parte, la sola reducción de nacimientos no cambiará el estado de la salud y el desarrollo.

Cuando los países formulan sus políticas de población éstas deben ser coherentes con su política de salud y el desarrollo deberá basarse en éstas. El sector salud debe promover la clarificación de las interrelaciones entre salud, desarrollo económico y social y la dinámica de la población, y medir estas relaciones tanto como sea posible de modo de incorporar estos nuevos conocimientos dentro de su planificación.

Cuando se piensa de manera específica en Brasil, país con una gran área geográfica, un gran contingente de población y enormes recursos naturales, no pensamos que una nación con semejantes características necesite de una política de control poblacional para resolver sus problemas de subdesarrollo, sino más bien que los cambios estructurales y políticos conducirían a un armonioso desarrollo social y económico. Sin embargo, esto no impide la existencia de planeación familiar para los individuos y sus familias, a través de centros de atención infantil y maternal, de modo de ofrecer asistencia médica global e integral. Es de la sola competencia de cada nación soberana decidir sobre su propia política sin la imposición de organismo internacional alguno.

\section{Aspectos DEMOGRÁficos en LATINOAMÉRICA}

La situación y evolución demográfica de América Latina ha sido objeto de creciente preocupación en los últimos años, ya que es una de las zonas de más rápido crecimiento en el mundo. Las principales cifras demográficas de Latinoamérica y su comparación con las mundiales se presentan en el cuadro 3 . 
Cuadro 3

TENDENCIAS de LA POBLACIÓN Y ESTAdísticas vitales DEL MUNDO Y DE AMÉRICA LATINA

\begin{tabular}{|c|c|c|}
\hline Concepto & Hundial & $\begin{array}{l}\text { Amórica } \\
\text { Latina }\end{array}$ \\
\hline \multicolumn{3}{|l|}{ Poblacion (millones) } \\
\hline $\begin{array}{l}1950 \\
1960 \\
1970 \\
1971 \text { (estimada) } \\
1980 \text { (proyectada) } \\
\text { Incremento, 1950-1980 (\%) }\end{array}$ & $\begin{array}{rr}2 & 486 \\
2 & 982 \\
3 & 632 \\
3 & 706 \\
4 & 457 \\
& 79\end{array}$ & $\begin{array}{l}162 \\
213 \\
203 \\
291 \\
373 \\
130\end{array}$ \\
\hline \multicolumn{3}{|c|}{ Tasas amuales por cade 1000 habitantes } \\
\hline \multicolumn{3}{|l|}{ Perfodo 1965-1970 } \\
\hline $\begin{array}{l}\text { Nacinientors } \\
\text { Kuertos } \\
\text { Incremento natue.] } \$ \text { / }\end{array}$ & $\begin{array}{l}33.8 \\
14.0 \\
19.8\end{array}$ & $\begin{array}{l}38.4 \\
10.0 \\
28.4\end{array}$ \\
\hline \multicolumn{3}{|c|}{ Partodo 1970-1975 (proyectadas) } \\
\hline $\begin{array}{l}\text { Nacimientos } \\
\text { Kuertes } \\
\text { Increnento natural af }\end{array}$ & $\begin{array}{l}33.2 \\
12.8 \\
20.4\end{array}$ & $\begin{array}{r}37.6 \\
8.9 \\
28.7\end{array}$ \\
\hline \multicolumn{3}{|c|}{ E'speranza de vida al nacer, anbos sexos } \\
\hline $\begin{array}{l}1965-1970 \\
1970-1975\end{array}$ & $\begin{array}{l}53.1 \\
55.5\end{array}$ & $\begin{array}{l}60.2 \\
62.5\end{array}$ \\
\hline
\end{tabular}

Fuente: Population Council, "Reportes sobre población: Planificación familiar". Núm. 2, 4a edición, septiembre de 1972.

Nacimientos menos defunciones.

b En años.

La población de los 20 países que componen América Latina, representa alrededor del $8 \%$ de la población mundial, distribuida en $19976040 \mathrm{~km}^{2}$, con una densidad media de 13.8 habitantes por kilómetro cuadrado. Mediante una clasificación territorial de cada país, las Naciones Unidas presentan la situación latinoamericana por grandes áreas (véase el cuadro 4).

Los valores extremos de densidad de población en América Latina corresponden por un lado a Haití con 188.4 habitantes por kilómetro y por el otro Bolivia con 4.2. Centroamérica tiene una densidad promedio de 34.8 con El Salvador como el país más densamente poblado de la región, 164.4 habitantes por kilómetro.

Se puede establecer otra clasificación territorial, como la que aparece en el cuadro 5, y en la que se utiliza el tamaño de la población de los países más importantes. De acuerdo con tal criterio, Brasil y México tienen más del $50 \%$ de la población latinoamericana; y este último ocuparía el octavo lugar en el mundo en cuanto a población y el quinto en superficie.

Como puede verse en el cuadro 5 , existe poca variabilidad en las densidades de distintas áreas, con la excepción de Centroamérica y México. 
Cuadro 4

América latina: Población, territorio y densidad POR GRANDES REGIONES, 1970

\begin{tabular}{|c|c|c|c|}
\hline Regi6n & Poblao16na & Saperpiolo & Dons Ldado \\
\hline 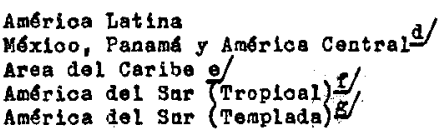 & $\begin{aligned} 274935 \\
67146 \\
17918 \\
150431 \\
39440\end{aligned}$ & $\begin{array}{rrr}19 & 976 & 040 \\
2 & 474 & 645 \\
& 190 & 716 \\
13 & 198 & 578 \\
4 & 112 & 101\end{array}$ & $\begin{array}{l}13.8 \\
27.1 \\
94.0 \\
11.4 \\
9.6\end{array}$ \\
\hline
\end{tabular}

a Miles de habitantes.

b Kilómetros cuadrados.

c Habitantes por kilómetro de superficie.

d América Central: Costa Rica, El Salvador, Guatemala, Honduras y Nicaragua.

e Cuba, Haití y República Dominicana.

f Bolivia, Brasil, Colombia, Ecuador, Perú y Venezuela.

g Argentina, Chile, Paraguay y Uruguay.

Cuadro 5

América latina: Población, territorio y densidad EN LOS PRINCIPALES Países Y GRUPOS DE PAÍSES, 1970

\begin{tabular}{|c|c|c|c|}
\hline Pala o reglon & Poblac16n & Superficie & Densidad \\
\hline $\begin{array}{l}\text { Ambrica Latiaa } \\
\text { Braall } \\
\text { Merioo } \\
\text { America Central } \\
\text { Grapo Aadino d/, } \\
\text { Otros palaes } \theta /\end{array}$ & $\begin{array}{rl}274 & 935 \\
93 & 244 \\
50 & 718 \\
15 & 022 \\
66 & 967 \\
48 & 984\end{array}$ & $\begin{array}{rrr}19 & 976 & 040 \\
8 & 511 & 965 \\
1 & 967 & 183 \\
431 & 812 \\
5 & 428 & 380 \\
3 & 636 & 700\end{array}$ & $\begin{array}{l}13.8 \\
11.0 \\
25.8 \\
34.8 \\
12.3 \\
13.5\end{array}$ \\
\hline
\end{tabular}

Fuente: Organización Panamericana de la Salud, "Salud y población", Publicación Científica, Núm. 232, p. 44, 1971.

a Miles de habitantes.

b Kilómetros cuadrados.

c Habitantes por kilómetro de superficie.

d Bolivia, Colombia, Chile, Ecuador, Perú y Venezuela.

e Argentina, Cuba, Haití, Panamá, Paraguay, República Dominicana y Uruguay.

De acuerdo con cálculos recientes, la población latinoamericana se incrementó en 36702000 habitantes en el quinquenio 1965-1970, lo que representa un aumento del $15.4 \%$ de la población estimada en 1965 , esto es, un crecimiento medio anual de $2.91 \%$, mientras que entre 1960 y 1965 el crecimiento fue de $2.86 \%$ anual. La tasa media de crecimiento observada en esos cinco años es la más alta jamás vista en la historia demográfica. En Latinoamérica, y para ambos grupos mencionados, el crecimiento de 1965 a 1970 se presenta en el cuadro 6.

El nivel de la tasa de crecimiento en Latinoamérica como un todo es cercana a la de África (2.6\%), seguidas de la de Asia (2.3\%), Oceanía $(1.9 \%)$ y Europa $(0.8 \%)$. De acuerdo con tal ritmo de crecimiento, 


\section{Cuadro 6}

América latina: Crecimiento de población por regiones, 1965-1970

\begin{tabular}{|c|c|c|c|c|c|c|}
\hline \multirow{2}{*}{ Region } & \multirow[b]{2}{*}{ Poblacior } & \multicolumn{2}{|c|}{ Crecimiento } & \multirow{2}{*}{$\begin{array}{c}\text { Tasa de } \\
\text { crecimiento } \\
\text { anual } \\
(\%)\end{array}$} & \multirow{2}{*}{$\begin{array}{c}\text { Poblacion } \\
1970\end{array}$} & \multirow{2}{*}{$\begin{array}{l}\text { Junero de } \\
\text { años necesa } \\
\text { ros para } \\
\text { duplicarse }\end{array}$} \\
\hline & & $\begin{array}{l}\text { sbooluto } \\
1955-1970^{a}\end{array}$ & $\begin{array}{c}\text { respecto } \\
\text { habitantes } \\
\text { en } 1965 \text { (\%) }\end{array}$ & & & \\
\hline Americe Latina & 238233 & 36702 & 15.4 & 2.91 & 274935 & 23.8 \\
\hline \multicolumn{7}{|l|}{$\frac{\text { Primera clasifi- }}{\text { cecib́n }}$} \\
\hline \multirow{3}{*}{ 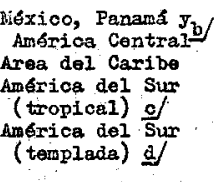 } & $\begin{array}{ll}56 & 724 \\
15 & 857\end{array}$ & $\begin{array}{r}10422 \\
2061\end{array}$ & $\begin{array}{l}18.4 \\
13.0\end{array}$ & $\begin{array}{l}3.41 \\
2.47\end{array}$ & $\begin{array}{l}67146 \\
17918\end{array}$ & $\begin{array}{l}20.2 \\
28.1\end{array}$ \\
\hline & 129640 & 20791 & 16.0 & 3.02 & 150431 & 23.0 \\
\hline & 36012 & 3428 & 9.5 & 1.84 & 39440 & 37.7 \\
\hline \multicolumn{7}{|l|}{$\frac{\text { Segunda clasifi- }}{\text { cacion }}$} \\
\hline $\begin{array}{l}\text { Brasil } \\
\text { Rírico } \\
\text { America Central } \\
\text { Grupo Ardino } \\
\text { Otros pafses }\end{array}$ & $\begin{array}{ll}80 & 953 \\
42 & 696 \\
12 & 831 \\
57 & 395 \\
44 & 358\end{array}$ & $\begin{array}{rl}12 & 291 \\
8 & 022 \\
2 & 191 \\
9 & 572 \\
4 & 626\end{array}$ & $\begin{array}{l}15.2 \\
13.8 \\
17.1 \\
16.7 \\
10.4\end{array}$ & $\begin{array}{l}2.87 \\
3.50 \\
3.20 \\
3.13 \\
2.00\end{array}$ & $\begin{array}{ll}93 & 244 \\
50 & 718 \\
15 & 022 \\
66 & 967 \\
48 & 984\end{array}$ & $\begin{array}{r}24.2 \\
19.8 \\
4.7 \\
22.2 \\
34.7\end{array}$ \\
\hline
\end{tabular}

Fuente: Organización Panamericana de la Salud, "Salud y población", Publicación Científica, Núm. 232, 1971, p. 46.

a Miles de habitantes.

b Véase la nota $d$ del cuadro 4 .

c Véase la nota $f$ del cuadro 4.

d Véase la nota $g$ del cuadro 4 .

Latinoamérica necesita menos de 24 años para duplicar su población, mientras que a comienzos de siglo requería de 40 años.

Si se mantuviera el mismo ritmo de crecimiento como el observado entre 1965 y 1970, la población de América Latina prácticamente igualará en 1985 a la esperada para Europa (exceptuando el Reino Unido y Escandinavia): 422520000 habitantes contra 425448000 en Europa. Miró clasificó los 20 países latinoamericanos en cuatro grupos de acuerdo con su comportamiento demográfico, asociado con otros índices socioeconómicos tales como urbanización, nivel de analfabetismo, proporción de hombres trabajando en actividades primarias, e ingreso per capita:

Grupo I: Argentina y Uruguay, que representan el $10 \%$ de la población total de la zona. Estos países registraron tasas de fecundidad y mortalidad reducidas, al mismo tiempo que una baja tasa de crecimiento natural. También son los dos países con las menores proporciones de habitantes menores de 15 años, de analfabetas, de hombres dedicados a las actividades primarias, y con los más altos porcientos de urbanización e ingreso per capita.

Grupo II: Cuba y Chile, con $7 \%$ de la población total. La mortalidad ha descendido significativamente y ha comenzado un ligero descenso en la fertilidad. El crecimiento de la población puede considerarse moderado y, después del Grupo I, registran las menores proporciones de 
menores de 15 años, de analfabetas, y de gentes dedicadas a las actividades primarias así como los más altos grados de urbanización e ingreso per capita.

Grupo III: En este grupo se incluyen Bolivia y Haití, los cuales tienen una moderada tasa de crecimiento (alrededor de $2.5 \%$ ) debido a una alta tasa de fecundidad combinada con una mortalidad que muestra pocas señales de disminución. Estos países cuentan con el $4 \%$ de la población total, y registran los índices de analfabetismo más altos, de gente en actividades primarias, y la más baja urbanización e ingreso per capita de la región.

Grupo IV: Este grupo está formado por los otros 14 países, con el $79 \%$ de la población total. La mortalidad ha tenido un fuerte descenso, llegando a niveles medianos o bajos, combinándose con una fecundidad relativamente estable y alta, lo que conduce a una alta tasa de crecimiento la cual continúa creciendo (alrededor del $3.0 \%$, y en algunos países $3.5 \%$ ). La población menor de 15 años es del 42 al $47 \%$ del total; el porciento de urbanización no llega a $30 \%$, con la excepción de $\mathrm{Pa}$ namá; el analfabetismo es de un $62 \%$; la gente dedicada a actividades primarias es más de $55 \%$ con la excepción de Venezuela; y el ingreso per capita no llega a los 380 dólares anuales, excepto para México, Venezuela, y recientemente Brasil.

La población latinoamericana tiene dos características comunes: una desigual distribución geográfica, y una proporción elevada de población joven, lo que hace que la fuerza de trabajo crezca rápidamente.

Paradójicamente, América Latina continúa siendo un continente rural, con población muy dispersa en vastas áreas.

\section{LA TASA DE NATALIDAD Y SU RELACIÓN CON PATRONES CULTURALES}

En América Latina predomina la religión católica. Es entonces lógico preguntarse: ¿tienen los países católicos una tasa de natalidad mayor? Un trabajo importante publicado por el Population Reference Bureau dice: "El subdesarrollo más que la iglesia católica es responsable de la elevada tasa de natalidad en América Latina" [14].

Un error muy frecuente es suponer que las tasas de natalidad elevadas de algunos países católicos, en particular de los subdesarrollados, obedecen a la influencia de la iglesia católica, o a la devoción de la gente hacia sus prácticas religiosas.

Las estadísticas demográficas muestran, por otra parte, que existe una relación directa de las altas tasas de natalidad con el subdesarrollo, en particular entre gente de bajo nivel educativo. En otras regiones tan católicas como América Latina, pero de países desarrollados, como Hungría, tan profundamente católica, se muestran tasas de natalidad reducidas.

Las estadísticas de Naciones Unidas demuestran que muchos países 
predominantemente católicos tienen las más bajas tasas de natalidad jamás registradas. Asimismo, el ingreso per capita en los países católicos de Europa varía entre 350 y 1500 dólares, con una media mayor que la de la mayoría de los países no católicos de África y Asia.

De acuerdo con los demógrafos, el hecho de ser o no católico, no implica una tasa de natalidad distinta, ya que ésta la determina el grado de desarrollo económico alcanzado por los países. En los países industrializados de occidente, la revolución industrial condujo à una reducción gradual en la mortalidad junto con un incremento en el alfabetismo, y estas dos tendencias llevaron a una lenta y espontánea baja en las tasas de natalidad. Como regla general, la tendencia decreciente de la tasa de natalidad aparece sólo una generación después de que se reduce la mortalidad, y por lo tanto la diferencia entre nacimientos y muertes no es 10 suficientemente grande como para causar una "explosión demográfica" tal y como se usa esta expresión hoy día.

La diferencia creciente entre nacimientos y muertes, la causa directa del rápido incremento de la población, puede observarse en países católicos y no católicos, aunque también se da una tendencia en los últimos tiempos hacia bajas tasas de mortalidad y natalidad tanto en países católicos como en no católicos.

¿Qué clase de repercusión tuvo la religión católica en Europa? Como un todo, los 11 países católicos europeos tienen una tasa de natalidad de 18.1 nacidos vivos por millar de habitantes, y en los otros 15 países no católicos la media es la misma. Así que en Europa no existe evidencia que indique que el catolicismo ejerce alguna influencia en el incremento de la tasa de natalidad.

En el mundo occidental la transición histórica de grandes a pequeñas familias tuvo sus comienzos, de modo significativo, en dos países católicos: Francia e Irlanda.

América Latina es una zona en donde el catolicismo convive con altas tasas de natalidad. Como resultado de la medicina moderna y las medidas de salud pública, la mortalidad ha descendido en unos cuantos decenios, y ahora es apenas un poco mayor que en los Estados Unidos u otros países desarrollados. Sin embargo, en ninguna otra región del planeta se presenta una tasa "moderna de mortalidad junto con una tasa "tradicional" de natalidad.

No hay duda que para América Latina, donde predomina la religión católica, existen razones de importancia que conducen a atribuir más a los factores económicos que a las doctrinas religiosas. La influencia de la iglesia en contra de los programas de control de natalidad es muy fuerte, aunque cada vez es menor, pero con frecuencia se exagera el grado de control que ejerce sobre el comportamiento sexual dentro de las familias. A través de investigaciones hechas por el Centro Latinoamericano de Demografía (CELADE) de Naciones Unidas, y la Universidad de Cornell, en seis ciudades latinoamericanas [14], se encontró una notable falta de influencia de la religión en el número de niños que las 
mujeres tienen, utilizando como medida de religiosidad la frecuencia de la asistencia a misa. Estos estudios demostraron que las mujeres católicas "devotas" tienen un número medio menor de hijos que aquellas que son católicas sólo "de nombre". Por otra parte, sí existe una alta relación entre nivel de educación y fecundidad. En algunas de las ciudades incluidas en el estudio de cELADE, las mujeres de bajo nivel educativo tienen al menos un hijo más que aquellas de alto nivel educacional, de manera independiente del grado de convicción religiosa. Así, en lo que concierne a la elevada tasa de fecundidad, el nivel económico y cultural de América Latina, antes que las creencias religiosas, es lo que hace que se esté al mismo nivel que África y Asia.

Por último, las evidencias demográficas no proporcionan fuerza alguna a las teorías de que la iglesia ejerce influencia en contra del control de la población. Se ha visto que en Europa, donde las tasas de natalidad son bajas, no existe diferencia entre países católicos y no católicos.

En América Latina, donde las tasas de natalidad son altas, la religión guarda menor importancia que el desarrollo, en especial en lo que respecta a alfabetismo e ingreso.

\section{BosQuejo histórico de la planeAción FAMILIAR EN LA REgión}

Hasta 1965, prácticamente no existía planeación familiar en esta región. La mayoría de los programas comenzaron como movimientos iniciados por ginecólogos y especialistas en obstetricia y salud pública, como alternativas del aborto inducido, sobre el cual las estadísticas mostraban que comenzaba a ser un problema serio de salud pública en la zona. Esto se debía al alto riesgo de mortalidad interna y al elevado costo del tratamiento de complicaciones. La Federación Internacional de Planeación Familiar (hemisferio occidental) al aceptar estos hechos como básicos, aumentó sus actividades en la región. La resultante fue la fundación de asociaciones nacionales de planeación familiar en todos los países del continente, con excepción de Bolivia y Haití.

En el desarrollo de estas actividades participaron varias organizaciones privadas tales como la AID, las Fundaciones Rockefeller y Ford, Pathfinder, Victor y el Consejo de Población. Pagaron entrenamiento, equipo y anticonceptivos y financiaron al personal de las clínicas a través de acuerdos con gobiernos y universidades, y con los departamentos de obstetricia, ginecología, higiene y medicina preventiva de las escuelas de medicina.

Gracias a estos esfuerzos se registró un incremento constante en el número de clínicas de planeación familiar en América Latina. En 1969 eran 882, el $65 \%$ de ellas en hospitales de gobierno y en clínicas de consulta externa. Se estima que ahora su número es de alrededor de 1000 , con la mayoría de ellas en áreas urbanas. 
Si se utiliza como indicador el porciento de mujeres protegidas en edad fértil, los países donde la planeación familiar está menos desarrollada son: Argentina, Bolivia, Brasil, Cuba, Haití, México y Dominicana. Por otra parte, si se considerara como índice el consumo mensual de anticonceptivos orales vendidos en las farmacias sin receta médica, el porciento de mujeres protegidas sería mayor.

Sólo Chile y Colombia están mejor organizados en su intento de lograr que los programas de planeación familiar abarquen a la totalidad del país [4].

\section{Cuadro 7}

AmÉrica Latina: Usuarios de SERvicios de Planeación familiar, Por MÉTODO Y AÑO DE LA ACEPTACIÓN, CON EL PROGRAMA NACIONAL DE PLANEACIÓN FAMILIAR O CON EL PROGRAMA DE PLANEACIÓN post partum, 1967-1971 a

\begin{tabular}{lccccc}
\hline & $\begin{array}{c}\text { Todos los } \\
\text { métoùos }\end{array}$ & DIU & $\begin{array}{c}\text { Contraceptivos } \\
\text { orales }\end{array}$ & $\begin{array}{c}\text { Estęrili- } \\
\text { zacion }\end{array}$ & $\begin{array}{c}\text { Otros } \\
\text { mé todos }\end{array}$ \\
\hline 1967 & 23.8 & 18.5 & 3.0 & 2.1 & 0.1 \\
1968 & 25.8 & 19.0 & 4.0 & 2.5 & 0.3 \\
1969 & 47.1 & 26.7 & 16.4 & 2.5 & 1.5 \\
1970 & 59.6 & 29.3 & 25.9 & 1.6 & 2.9 \\
1971 & 78.7 & 35.1 & 37.6 & 1.8 & 4.2 \\
$1966-1971$ & 248.5 & 139.2 & 88.4 & 11.7 & 9.1 \\
\hline
\end{tabular}

Fuente: Population Council, "Reportes sobre población: Planificación familiar" Núm. 2, 4a edición, septiembre de 1972.

a El número de usuarios se expresa en miles y se refiere sólo a los programas ya sea nacionales o internacionales (las sumas por subcategorías pueden no coincidir con el total por efecto del redondeo de cifras).

Por su parte, en Brasil el movimiento en favor de la planificación familiar ha sido dirigido por el BENFAM (Sociedad civil de Bienestar Familiar) fundado en noviembre de 1965. En sus siete años de existencia, el número total de familias sujetas a planeación familiar fue de 81 hasta finales de 1972 [1].

\section{Objetivos de los programas}

Los objetivos de los programas difieren de un país a otro aunque tienen un elemento en común, dado que en todos se establecen propósitos de salud: reducción de problemas de salud derivados de la práctica del aborto inducido, reducción de la mortalidad maternal y de la mortalidad infantil. Algunos países, además de los propósitos sobre salud, establecen de manera explícita como objetivo disminuir la fecundidad tanto en términos de corto como de largo plazo, así como contribuir a la solución de los problemas económicos y sociales. Los países que especifican en sus programas objetivos de salud en forma exclusiva son: Brasil 


\section{Cuadro 8}

MORTAlidad INFANTIL $Y$ NEONATA a POR EDAD DE LA MADRE AL NACIMIENTO DEL INFANTE EN SIETE PROYECTOS

\begin{tabular}{|c|c|c|c|c|c|c|c|}
\hline $\begin{array}{l}\text { Edad de } \\
\text { Ia madre } \\
\text { (años) }\end{array}$ & $\begin{array}{l}\text { Argentina } \\
\text { Provinoia } \\
\text { del Chaco }\end{array}$ & $\frac{\text { Bragat }}{\text { Sä Paulo }}$ & $\frac{\text { Canads }}{\text { Sherbrooko }}$ & Cntle & $\frac{\text { E1 Salva- }}{\text { dor }}$ & $\frac{\text { Hexioo }}{\text { Honterrey }}$ & $\frac{\frac{\text { Estados }}{\text { Unidos }}}{\text { Cal1fornia }}$ \\
\hline & \multicolumn{7}{|c|}{ Mortalidad noonatal } \\
\hline Total & 32.3 & 33.7 & 13.5 & 26.6 & 29.6 & 26.0 & 12.7 \\
\hline Xenos de 20 & 53.4 & 52.3 & 16.4 & 31.7 & 40.7 & 33.1 & 17.2 \\
\hline $20-24$ & 28.3 & 32.1 & 12.6 & 24.2 & 26.2 & 23.9 & 11.7 \\
\hline $25-29$ & 26.6 & 28.7 & 12.9 & 23.2 & 23.7 & 20.7 & 11.3 \\
\hline $30-34$ & 31.9 & 34.3 & 16.1 & 29.9 & 27.6 & 27.2 & 12.7 \\
\hline 35 g mâ: & 27.1 & 37.2 & 12.8 & 30.2 & 34.5 & 34.1 & $\$ 4.0$ \\
\hline \multicolumn{8}{|c|}{ Hortalidad infantil } \\
\hline Total & 80.1 & 65.1 & 18.3 & 55.2 & 88.4 & 60.7 & 17.5 \\
\hline Manog de 20 & 133.5 & 104.1 & 21.2 & 79.3 & 916.6 & 86.3 & 26.2 \\
\hline $20-24$ & 76.6 & 67.9 & 18.6 & 51.7 & $\dot{84.2}$ & 59.7 & 15.9 \\
\hline $25-29$ & 60.5 & 53.2 & 16.5 & 44.5 & 72.9 & 47.0 & 15.3 \\
\hline $30-34$ & 69.4 & 61.4 & 18.3 & 53.1 & 81.3 & 56.8 & 16.5 \\
\hline 35 g más & 72.8 & 67.4 & 20.3 & 59.8 & 93.6 & 77.4 & 17.5 \\
\hline
\end{tabular}

Fuente: Organización Panamericana de la Salud, "Patrones de mortalidad en la niñez", Publicación Científica, Núm. 262, 1973.

a Muertes por cada mil nacidos vivos.

(recientemente), Colombia, Costa Rica, Cuba, Chile, Ecuador, El Salvador, Haití y Panamá. Por otra parte, aquellos que, aparte de los objetivos de salud, especifican objetivos de carácter demográfico son: Barbados, Guatemala, Jamaica, República Dominicana y Trinidad-Tobago.

\section{Desarrollo de los programas}

A pesar del hecho de que en la mayoría de los países se logró motivar y despertar el interés de las autoridades gubernamentales acerca de la necesidad de iniciar actividades de planeación familiar, en aquellos en los que más o menos se definieron metas precisas, éstas no se alcanzaron. En algunos casos esto se debió al hecho de que las metas no estaban de acuerdo con los recursos disponibles, ni con la organización realmente existente de servicios sanitarios, en los que deberían funcionar los programas de planeación familiar. Por otra parte, algunas veces estaban fuera de las posibilidades reales, por ejemplo Chile cubrió el $60 \%$ de las metas propuestas, y El Salvador únicamente el $2 \%$.

La mayoría de los países que crearon programas gubernamentales de planeación familiar, con la excepción de Barbados, Costa Rica y la Dominicana, deseaban que funcionara conjuntamente con servicios de asistencia materno-infantil. En la práctica esta integración ocurrió de modo 
limitado, ya que estos servicios de cuidados materno-infantiles son insuficientes en todos los países, y resultan incapaces de servir como base eficiente para los programas de planeación familiar. Por otra parte, un gran número de mujeres en edad fértil, clientes potenciales de estos programas, no utilizan los servicios de salud materno-infantil, y por lo tanto quedan fuera de contacto con los programas de planeación familiar. Podemos mencionar que otro factor que influye en el hecho de que los organismos que financian los programas, prefieren una organización administrativa de planeación familiar en forma de actividad vertical, y no horizontal, es decir, prefieren que se integre dentro de un programa global de salud.

Todavía se nota en la mayoría de los países la presencia de los siguientes hechos: falta de coordinación de la administración técnica de los programas, información estadística incompleta y poco confiable, inadecuada organización para seguir a los pacientes que abandonan el programa, y atención a población predominantemente urbana.

Todas estas limitaciones observadas en relación con la planeación familiar son también válidas para los programas generales de salud.

El cuadro 7 muestra algunas cifras de usuarios de servicios de planeación familiar en Latinoamérica, y los métodos escogidos o empleados.

\section{RELACIONES OBSERVADAS ENTRE TAMAÑo DE LA FAMILIA $Y$ MORTALIDAD INFANTIL}

\section{Mortalidad neonatal e infantil por edad de la madre}

Puffer y Serrano (1973) proporcionan datos interesantes en su estudio "Patrones de mortalidad en la Niñez". El Cuadro 8 y las gráficas 1 y 2 muestran la mortalidad neonatal e infantil en siete proyectos (cinco en Latinoamérica y dos en Norteamérica) por edad de la madre en cinco grupos de edad.

En todos los cinco proyectos latinoamericanos, la tasa de mortalidad más baja se da en los niños con madres en el grupo de edad 25-29. Es más alta para los niños de madres jóvenes y para aquellos de madres de 35 y más años de edad. "De los datos del estudio sobre Chile se desprende claramente que cuando la tasa de mortalidad infantil es baja, las curvas de mortalidad neonatal e infantil están más cercanas entre sí, que cuando la mortalidad neonatal observada en Chile, en madres menores de los 20 años (31.7 por cada 1000 nacidos vivos) fue mucho menor que la de São Paulo (52.3). Sin embargo, los patrones de mortalidad neonatal en los varios programas son similares en general, con menos diferencias que los observados en mortalidad infantil" [15].

En Sherbrooke y California las tasas de mortalidad son mucho más bajas que en los cinco programas latinoamericanos (debido principalmente a la influencia de la diferencia de clases sociales). "En esos dos 


\section{Gráfica 1}

Mortalidad NEONATAL E INFANTIL POR EDAD DE LA MADRE EN CINCO PROYECTOS LATINOAMERICANOS

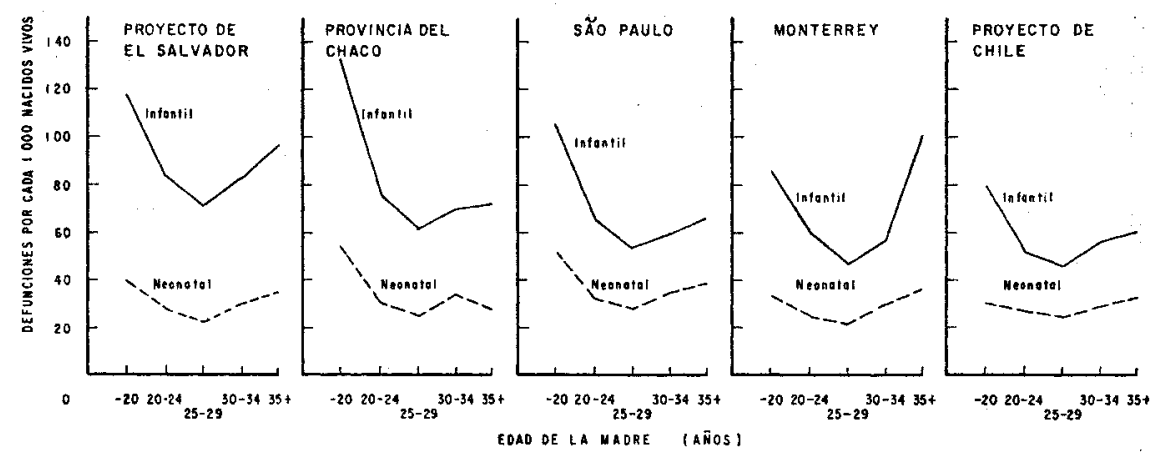

Fuente: Organización Panamericana de la Salud, "Patrones de mortalidad en la niñez", Publicación Científica, Núm. 262, 1973.

programas, la mortalidad infantil que asimismo más baja para los productos de madres de 25 a 29 años de edad y más alta para aquellos de madres más jóvenes. Las cifras son pequeñas en Sherbrooke, las que posiblemente siguen la distribución usual de mortalidad neonatal, la tasa es menor en niños de madres de 35 años de edad y más. La diferencia en estos moldes indica que la edad de la madre al nacimiento del niño es una determinante primordial de los niveles de mortalidad neonatal e infantil. Los niños nacidos de madres jóvenes (menores de 20 años) y de madres mayores (35 años y más) experimentaban la más alta morta-

\section{Gráfica 2}

MoRTALIDAD NEONATAL E INFANTIL POR EDAD DE LA MADRE EN LOS PROYECTOS DE SHERbROOKE Y CALIForNia

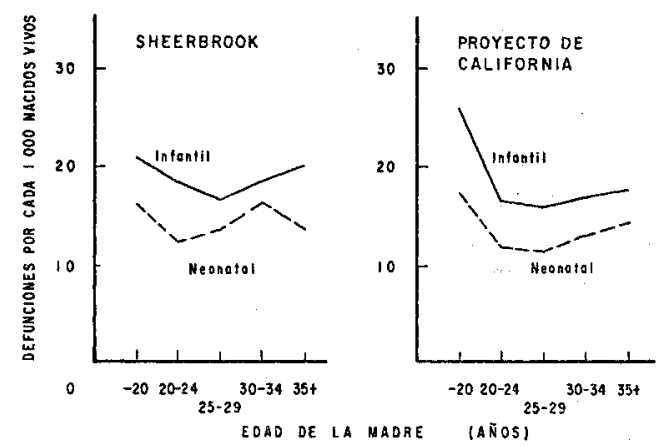

Fuente: Organización Panamericana de la Salud, "Patrones de mortalidad de la niñez”, Publicación Científica, Núm. 262, 1973. 
YUNES: EL PEDIATRA Y LOS CAMBIOS DE POBLACION

lidad. Por lo tanto, es clara la necesidad de recolectar y analizar datos sobre el factor edad de la madre". [15].

\section{Muertes infantiles por orden de nacimiento}

El orden de nacimiento de los infantes muertos ha sido estudiado en la misma investigación mencionada antes [15]. La distribución de porcientos de muertes infantiles por orden del nacimiento se muestran en

\section{Cuadro 9}

MUERTES INFANTILES a POR ORDEN DE NACIMIENTO EN 15 PROYECTOS

\begin{tabular}{|c|c|c|c|c|c|c|c|}
\hline \multirow{2}{*}{ Proyecto } & \multirow{2}{*}{ Tota1 } & \multicolumn{6}{|c|}{ NǴmero } \\
\hline & & 1 & 2 & 3 & 4 & $\underset{\text { más }}{5, y}$ & $\begin{array}{c}\text { Desoono- } \\
\text { oido } \\
\end{array}$ \\
\hline \multicolumn{8}{|l|}{ Argentina } \\
\hline $\begin{array}{l}\text { Provinoia del Chaco } \\
\text { p } \mathrm{b} /\end{array}$ & $\begin{array}{l}1410 \\
100.0\end{array}$ & $\begin{array}{l}341 \\
24.6\end{array}$ & $\begin{array}{l}253 \\
18.2\end{array}$ & $\begin{array}{l}162 \\
11.7\end{array}$ & $\begin{array}{l}142 \\
10.2\end{array}$ & $\begin{array}{l}491 \\
35.3\end{array}$ & 21 \\
\hline 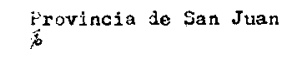 & $\begin{array}{l}1900 \\
100.0\end{array}$ & $\begin{array}{l}439 \\
23.8\end{array}$ & $\begin{array}{l}357 \\
19.4\end{array}$ & $\begin{array}{l}265 \\
14.4\end{array}$ & $\begin{array}{l}175 \\
9.5\end{array}$ & $\begin{array}{l}606 \\
32.9\end{array}$ & 58 \\
\hline$\frac{\text { Boliviz }}{6}$ & $\begin{array}{l}2790 \\
100.0\end{array}$ & $\begin{array}{l}603 \\
31.2\end{array}$ & $\begin{array}{l}392 \\
20.3\end{array}$ & $\begin{array}{l}236 \\
12.2\end{array}$ & $\begin{array}{l}211 \\
10.9\end{array}$ & $\begin{array}{l}488 \\
25.3\end{array}$ & 860 \\
\hline$\frac{\text { Arasil }}{k_{b}^{\text {kecifo }}}$ & $\begin{array}{l}2773 \\
100.0\end{array}$ & $\begin{array}{l}317 \\
13.7\end{array}$ & $\begin{array}{l}322 \\
13.9\end{array}$ & $\begin{array}{l}273 \\
11.8\end{array}$ & $\begin{array}{l}228 \\
9.9\end{array}$ & $\begin{array}{l}1174 \\
50.7\end{array}$ & 459 \\
\hline$\frac{\text { Ribeiräo Preto }}{i}$ & $\begin{array}{c}959 \\
100.0\end{array}$ & $\begin{array}{l}178 \\
21.1\end{array}$ & $\begin{array}{l}148 \\
17.5\end{array}$ & $\begin{array}{l}107 \\
12.7\end{array}$ & $\begin{array}{l}101 \\
12.0\end{array}$ & $\begin{array}{l}310 \\
36.7\end{array}$ & 115 \\
\hline$\underset{\substack{\text { São Paulo } \\
\text { and }}}{ }$ & $\begin{array}{l}3788 \\
100.0\end{array}$ & $\begin{array}{l}817 \\
24.1\end{array}$ & $\begin{array}{l}688 \\
20.3\end{array}$ & $\begin{array}{l}494 \\
14.6\end{array}$ & $\begin{array}{l}355 \\
10.5\end{array}$ & $\begin{array}{l}10.037 \\
30.6\end{array}$ & 397 \\
\hline$\frac{\text { Ganads }}{\frac{3}{6}}$ & $\begin{array}{l}310 \\
100.0\end{array}$ & $\begin{array}{c}83 \\
27.8\end{array}$ & $\begin{array}{c}71 \\
23.7\end{array}$ & $\begin{array}{l}55 \\
18.4\end{array}$ & $\begin{array}{c}32 \\
10.7\end{array}$ & $\begin{array}{c}58 \\
19.4\end{array}$ & 11 \\
\hline$\frac{\operatorname{cosile}}{6}$ & 2404 & $\begin{array}{l}581 \\
25.2\end{array}$ & $\begin{array}{l}497 \\
21.6\end{array}$ & $\begin{array}{l}347 \\
25.1\end{array}$ & $\begin{array}{l}235 \\
10.2\end{array}$ & $\begin{array}{l}643 \\
27.9\end{array}$ & 101 \\
\hline$\frac{\frac{\text { Golombia }}{\text { Gali }}}{g_{b}}$ & $\begin{array}{l}1153 \\
100.0\end{array}$ & $\begin{array}{l}172 \\
18.8\end{array}$ & $\begin{array}{l}159 \\
17.4\end{array}$ & $\begin{array}{l}133 \\
14.5\end{array}$ & $\begin{array}{l}116 \\
12.7\end{array}$ & $\begin{array}{l}335 \\
36.6\end{array}$ & 238 \\
\hline Cartigens & $\begin{array}{l}856 \\
100.0\end{array}$ & $\begin{array}{l}142 \\
19.3\end{array}$ & $\begin{array}{l}132 \\
13.0\end{array}$ & $\begin{array}{l}87 \\
11.9\end{array}$ & $\begin{array}{l}85 \\
11.6\end{array}$ & $\begin{array}{l}288 \\
39.2\end{array}$ & 122 \\
\hline$f^{b}$ & $\begin{array}{l}924 \\
100.0\end{array}$ & $\begin{array}{l}121 \\
15.7\end{array}$ & $\begin{array}{l}110 \\
14.3\end{array}$ & $\begin{array}{l}95 \\
12.4\end{array}$ & $\begin{array}{c}78 \\
10.1\end{array}$ & $\begin{array}{l}365 \\
47.5\end{array}$ & 155 \\
\hline B1, Salvador & $\begin{array}{l}2742 \\
100.0\end{array}$ & $\begin{array}{l}586 \\
22.0\end{array}$ & $\begin{array}{l}490 \\
19.4\end{array}$ & $\begin{array}{l}377 \\
14.2\end{array}$ & $\begin{array}{l}282 \\
10.6\end{array}$ & $\begin{array}{l}925 \\
34.8\end{array}$ & 82 \\
\hline Jamaica & & & & & & & \\
\hline Kineston-St. Andrew & $\begin{array}{l}1589 \\
100.0\end{array}$ & $\begin{array}{l}332 \\
21.7\end{array}$ & $\begin{array}{l}290 \\
19.0\end{array}$ & $\begin{array}{l}205 \\
13.4\end{array}$ & $\begin{array}{l}182 \\
11.9\end{array}$ & $\begin{array}{l}519 \\
34.0\end{array}$ & 61 \\
\hline 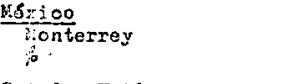 & 3220 & $\begin{array}{l}406 \\
15.0\end{array}$ & $\begin{array}{l}384 \\
14.2\end{array}$ & $\begin{array}{l}333 \\
12.3\end{array}$ & $\begin{array}{l}270 \\
10.0\end{array}$ & $\begin{array}{l}1317 \\
48.6\end{array}$ & 510 \\
\hline$\frac{\text { Estadoes Unidos }}{\text { Califurnia }}$ & $\begin{array}{c}784 \\
100.0\end{array}$ & $\begin{array}{l}241 \\
31.5\end{array}$ & $\begin{array}{l}211 \\
27.6\end{array}$ & $\begin{array}{l}136 \\
17.8\end{array}$ & $\begin{array}{c}35 \\
11.1\end{array}$ & $\begin{array}{l}92 \\
12.0\end{array}$ & 19: \\
\hline
\end{tabular}

Fuente: Organización Panamericana de la Salud, "Patrones de mortalidad en la niñez”, Publicación Científica, Núm. 262, 1973.

a Por mil nacidos vivos.

$b$ Los porcientos se calcularon sin tomar en cuenta los casos de la última columna. 


\section{Gráfica 3}

Provincia de Santiago: Distribución porcentual de nacidos VIVOS POR EDAD DE LA MADRE

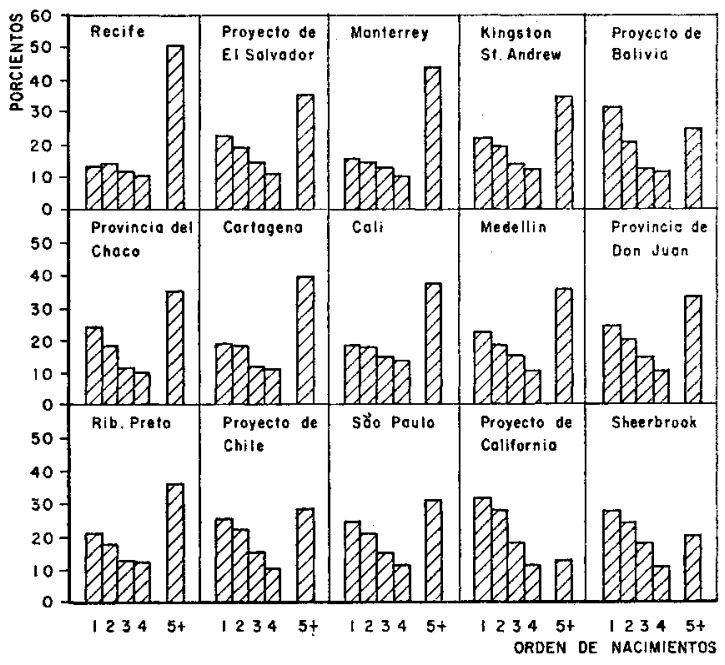

Gráfica 4

MUERTES INFANTILES POR ORDEN DE NACIMIENTO EN 15 PROYECTOS

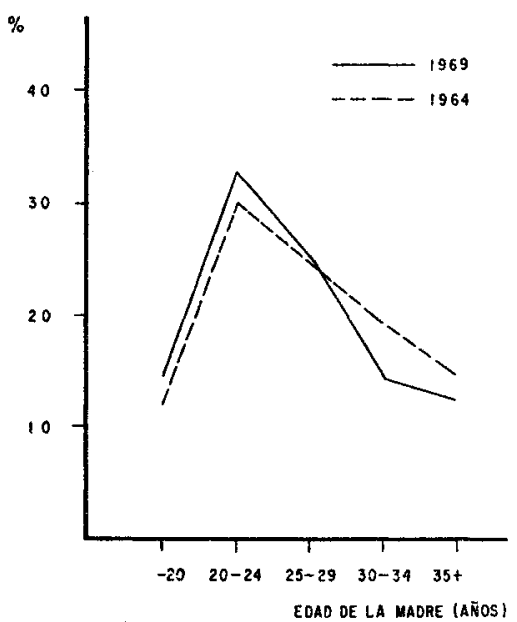

Fuente: Organización Panamericana de la Salud, "Patrones de mortalidad en la niñez", Publicación Científica, Núm. 262, 1973. 
el cuadro 9 y gráficas 3 y 4 para los 15 proyectos (13 de América Latina y dos de Norteamérica).

En Recife, con la más alta tasa de natalidad, más de la mitad de los infantes muertos fueron del quinto orden o mayor; sólo $13.7 \%$ fueron primeros nacimientos y $13.9 \%$ segundos. En Monterrey la norma fue similar, con $48.6 \%$ a partir del quinto nacimiento. El programa de Bolivia ${ }^{1}$ observó una inesperada distribución de muertes infantiles por orden de nacimiento. El más alto porciento de muertes ocurrió en los primeros nacimientos (31.2), y esta proporción es parecida a la del programa de California, donde $31.5 \%$ fueron primeros nacimientos. Sin embargo, para el resto de los órdenes de nacimiento las distribuiciones difieren en estos dos programas. En Bolivia $25.3 \%$ de las muertes infantiles fueron del quinto orden o mayor, mientras que en California el porciento fue sólo 12.0 [15].

En este estudio de cuatro proyectos, dos de ellos en América Latina, fue posible analizar la mortalidad neonatal e infantil de acuerdo con el orden de nacimiento.

Los dos proyectos latinoamericanos (Chile y Monterrey) tuvieron tasas semejantes de mortalidad infantil de primeros nacimientos, 39.4 y 40.5 por cada 1000 nacidos vivos, y parecidas y elevadas tasas de mortalidad para quintos nacimientos y posteriores, de 90.6 y 90.0 respectivamente (véase el cuadro 10 y las gráficas 5 y 6 ). Las tasas de morta-

Cuadro 10

MORTALIDAd NEONATAL E INFANTIL a POR ORDEN DE NACIMIENTO, EN CUATRO PROYECTOS

\begin{tabular}{|c|c|c|c|c|c|c|}
\hline \multirow{2}{*}{$\begin{array}{l}\text { Pais y tipo } \\
\text { da mortalidad }\end{array}$} & \multirow{2}{*}{ Total } & \multicolumn{5}{|c|}{ Orden de naoimiento } \\
\hline & & 9 & 2 & 3 & 4 & $5 y \mathrm{mbs}$ \\
\hline$\frac{\frac{\text { Chilo }}{\text { neonatal }}}{\text { Infantil }}$ & $\begin{array}{l}26.6 \\
55.2\end{array}$ & $\begin{array}{l}19.9 \\
39.4\end{array}$ & $\begin{array}{l}22.8 \\
47.8\end{array}$ & $\begin{array}{l}27.7 \\
57.8\end{array}$ & $\begin{array}{l}32.3 \\
67.0\end{array}$ & $\begin{array}{l}42.4 \\
90.6\end{array}$ \\
\hline 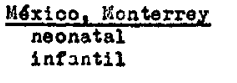 & $\begin{array}{l}26.0 \\
60.7\end{array}$ & $\begin{array}{l}19.5 \\
40.5\end{array}$ & $\begin{array}{l}18.9 \\
48.4\end{array}$ & $\begin{array}{l}19.4 \\
49.7\end{array}$ & $\begin{array}{l}23.9 \\
50.9\end{array}$ & $\begin{array}{l}38.1 \\
90.0\end{array}$ \\
\hline$\frac{\text { Canada, Shorbrooke }}{\begin{array}{c}\text { nsonatal } \\
\text { Intantil }\end{array}}$ & $\begin{array}{l}13.5 \\
18.3\end{array}$ & $\begin{array}{r}9.6 \\
12.6\end{array}$ & $\begin{array}{l}10.7 \\
16.3\end{array}$ & $\begin{array}{l}18.8 \\
23.7\end{array}$ & $\begin{array}{l}21.1 \\
27.3\end{array}$ & $\begin{array}{l}22.3 \\
30.5\end{array}$ \\
\hline 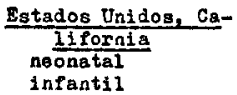 & $\begin{array}{l}12.7 \\
17.5\end{array}$ & $\begin{array}{r}8.9 \\
12.8\end{array}$ & $\begin{array}{l}12.1 \\
16.7\end{array}$ & $\begin{array}{l}16.2 \\
22.0\end{array}$ & $\begin{array}{l}21.8 \\
28.9\end{array}$ & $\begin{array}{l}23.5 \\
30.6\end{array}$ \\
\hline
\end{tabular}

Fuente: Organización Panamericana de la Salud, "Patrones de mortalidad en la niñez", Publicación Científica, Núm. 262, 1973.

a Tasas por mil nacidos vivos.

1 El número de muertes infantiles con orden de nacimiento desconocido fue grande en este proyecto, $\mathrm{y}$ no se conocen sus efectos en las estimaciones. 


\section{Gráfica 5}

MORTALIDAD INFANTIL $Y$ NEONATAL POR ORDEN DE NACIMIENTO EN LOS PROYECTOS DE CHILE Y MONTERREY

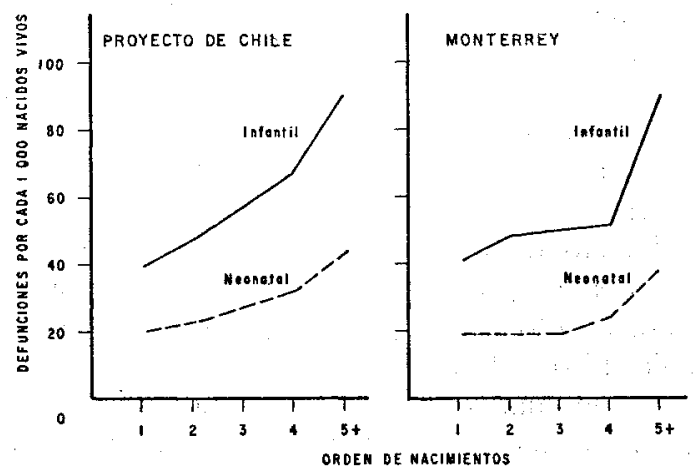

Fuente: Organización Panamericana de la Salud, "Patrones de mortalidad en la niñez”, Publicación Científica, Núm. 262, 1973.

lidad infantil en los estudios norteamericanos (California y Sherbrooke), fueron similares en general, crecientes respectivamente de 12.8 por cada 1000 nacidos vivos para primeros nacimientos, hasta 30.6 y 30.5 para aquellos de quinto orden y superior. En 11 programas latinoamericanos las proporciones de muertes infantiles en el grupo de quinto orden $y$ mayor fueron superiores a $30 \%$ :

Recife (50.7), Monterrey (48.6), Medellín (47.5), Cartagena (39.2) Riberao Preto (36.7), Cali (36.6), Provincia del Chaco (35.3), El Sal-

\section{Gráfica 6}

MORTAlidad INFANTIL Y NEONATAL POR ORDEN DE NACIMIENTo EN los proyectos de SHerbrooke y California

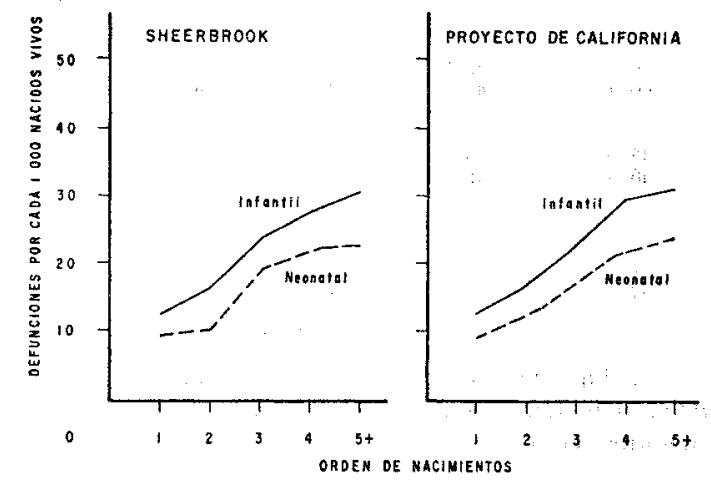

Fuente: Organización Panamericana de la Salud, "Patrones de mortalidad en la niñez”, Publicación Cientifica, Núm. 262, 1973. 
vador (34.8), Kingston-St. Andrew (34.0), Provincia de San Juan (32.9), y São Paulo (30.6). Los porcientos registrados en Chile y Bolivia fueron menores: 27.9 y 25.3, y para Sherbrooke y California mucho menores: 19.4 y 12.0 respectivamente.

Es entonces claro que el orden del nacimiento es un factor de gran importancia en la evolución de la mortalidad infantil [15].

Yunes (1967) [16], al revisar la literatura, encontró las mismas tendencias descritas antes para el Reino Unido y Estados Unidos. Menken (1972), estudió también las relaciones entre mortalidad infantil y edad de la madre en Estados Unidos, en 1960, y encontró las mismas tendencias $[10]$.

3. Relaciones entre ciertas causas de mortalidad neonatal, edad de la madre $y$ orden de nacimiento

a) Edad de la madre. Estas relaciones son de gran ayuda para el análisis de los factores conectados con la salud y supervivencia de los productos engendrados.

En cuatro proyectos [15], se puede identificar una norma en las relaciones entre mortalidad neonatal debida a ciertas causas perinatales (760-788) y la edad de la madre, siendo mayores las tasas de mortalidad neonatal en el caso de madres menores de 20 años (de 1286.5 a 2807.6 muertes por cada 100000 nacidos vivos), y más favorables en los grupos de edad 20-24 y 25-29. Por último, la mortalidad neonatal se incrementa de manera significativa conforme aumenta la edad de la madre, con tasas para madres de 35 y más que van de 1025.1 a 2297.0 por cada millón de nacidos vivos en los programas de California y São Paulo respectivamente (véase el cuadro 11).

$\mathrm{El}$ análisis de la mortalidad neonatal debida al nacimiento prematuro como causa fundamental o asociada, por edad de la madre, revela asi-

\section{Cuadro 11}

Mortalidad NeONatal a por ciertas causas perinatales SUBYACENTES POR EDAD DE LA MADRE

\begin{tabular}{|c|c|c|c|c|}
\hline $\begin{array}{l}\text { Edad de lo } \\
\text { madro } \\
\text { (ahoa) }\end{array}$ & $\begin{array}{c}\text { Bras1l } \\
\text { Sfo Panlo }\end{array}$ & B1 Salvador & $\begin{array}{c}\text { Moxico } \\
\text { Monterrey }\end{array}$ & $\begin{array}{c}\text { Batados } \\
\text { Onlios } \\
\text { Califorala }\end{array}$ \\
\hline $\begin{array}{l}\text { Total } \\
\text { manos do } 20 \\
20-24 \\
25=29 \\
30=34 \\
35 \text { I mas }\end{array}$ & $\begin{array}{ll}1 & 948.1 \\
2 & 807.6 \\
1 & 768.7 \\
1 & 706.4 \\
2 & 065.5 \\
2 & 297.0\end{array}$ & $\begin{array}{ll}1 & 731.1 \\
2 & 522.1 \\
1 & 612.4 \\
1 & 368.5 \\
1 & 484.2 \\
1 & 811.0\end{array}$ & $\begin{array}{ll}1 & 516.7 \\
2 & 131.5 \\
1 & 356.6 \\
1 & 290.8 \\
1 & 600.0 \\
1 & 768.5\end{array}$ & $\begin{array}{r}947.7 \\
1286.5 \\
864.4 \\
856.0 \\
935.1 \\
1025.1\end{array}$ \\
\hline
\end{tabular}

Fuente: Organización Panamericana de la Salud, "Patrones de mortalidad en la niñez", Publicación Científica, Núm. 262, 1973.

a Tasas por 1000 nacidos vivos. 
Cuadro 12

Mortalidad NEONATAL a DEBIDA a NACIMIENTOS PREMATuRos como CAUSA FUNDAMENTAL O SUBYACENTE, POR EDAD DE LA MADRE

\begin{tabular}{|c|c|c|c|c|}
\hline & $\frac{\text { Brasil }}{\text { Săo Paulo }}$ & El SeIvador & $\frac{\text { jexico }}{\text { vionterrey }}$ & $\frac{\text { Estaios }}{\text { Cantidos }}$ \\
\hline $\begin{array}{l}\text { Total } \\
\text { Uenos de } 20 \\
20-24 \\
25=29 \\
30-34 \\
35 \text { y más }\end{array}$ & $\begin{array}{ll}2 & 001.4 \\
3 & 682.9 \\
1 & 867.3 \\
1 & 613.0 \\
1 & 998.4 \\
2 & 223.5\end{array}$ & $\begin{array}{ll}1 & 711.8 \\
2 & 658.0 \\
1 & 701.2 \\
1 & 305.0 \\
1 & 297.0 \\
1 & 579.9\end{array}$ & $\begin{array}{ll}1 & 320.5 \\
1 & 993.0 \\
1 & 222.6 \\
1 & 075.0 \\
1 & 398.7 \\
1 & 483.7\end{array}$ & $\begin{array}{r}990.2 \\
456.0 \\
632.5 \\
824.5 \\
598.0 \\
1208.0\end{array}$ \\
\hline
\end{tabular}

Fuente: Organización Panamericana de la Salud, "Patrones de mortalidad en la niñez”, Publicación Científica, Núm. 262, 1973.

a Tasas por 100000 nacidos vivos.

mismo una relación interesante. Había una norma constante por la cual se utilizaron los datos sobre la edad de la madre (véase el cuadro 12 y la gráfica 7): las tasas de nacimientos prematuros eran de manera consistente más altas para las madres jóvenes (menores de 20) que para el resto de los grupos de edad, e iban de 1456.0 a 3682.9 por cada 100000 nacidos vivos, en los programas de California y São Paulo respectivamente. En todos los programas, las tasas más favorables eran para aquellos productos de madres de edad intermedia, y se notaron incrementos significativos en recién nacidos de madres de 35 años y más [15].

b) Orden de los nacimientos. Las relaciones entre el orden de los nacimientos y la mortalidad neonatal debida a ciertas causas perinatales

\section{Gráfica 7}

Mortalidad DEBida AL NACIMIENTo PREMATURo COMO CAUSA FUNDAMENTAL O SUBYACENTE, POR EDAD DE LA MADRE, EN CINCO PROYECTOS

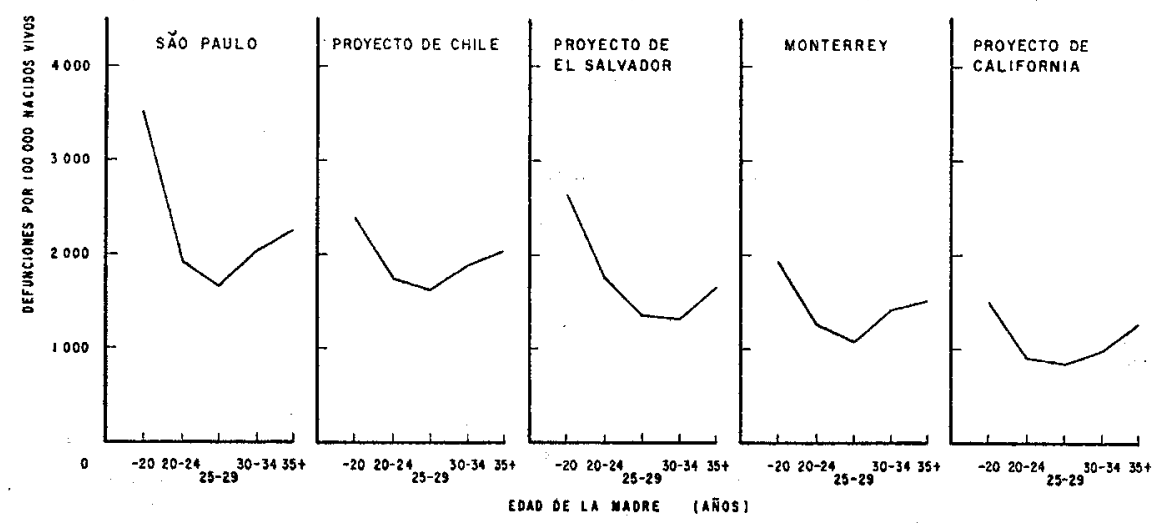

Fuente: Organización Panamericana de la Salud, "Patrones de mortalidad en la niñez", Publicación Científica, Núm. 262, 1973. 
pueden verse en el cuadro 13. Las tasas de mortalidad se incrementaron rápidamente después del primer nacimiento en dos de los tres programas y después del tercero en el de Monterrey. Los infantes de quinto orden de nacimiento o más tuvieron el mayor riesgo de morir de causas perinatales durante el período neonatal [15].

\section{Cuadro 13}

Mortalidad NEONATAL a DEBIDA A CiERTAS CAUSAS PERINATALES COMO CAUSAS SUBYACENTES, POR ORDEN DE NACIMIENTO, EN TRES PROYECTOS

\begin{tabular}{|c|c|c|c|}
\hline Orien do nacimiento & Chile & $\frac{\text { México }}{\text { Monterrey }}$ & $\frac{\text { Estalog Unidos }}{\text { Galifornis }}$ \\
\hline $\begin{array}{l}\text { Total } \\
1 \\
2 \\
3 \\
4 \\
\text { j y más }\end{array}$ & $\begin{array}{ll}1 & 858.7 \\
1 & 361.9 \\
1 & 626.9 \\
1 & 999.9 \\
2 & 168.1 \\
2 & 958.4\end{array}$ & $\begin{array}{ll}1 & 516.7 \\
1 & 219.8 \\
1 & 201.7 \\
1 & 151.4 \\
1 & 335.1 \\
2 & 125.0\end{array}$ & $\begin{array}{r}947.7 \\
646.1 \\
853.8 \\
1239.4 \\
1703.0 \\
1894.7\end{array}$ \\
\hline
\end{tabular}

Fuente: Organización Panamericana de la Salud, "Patrones de mortalidad en la niñez", Publicación Científica, Núm. 262, 1973.

a Tasas por 100000 nacidos vivos.

En esos mismos proyectos se encontró una relación aún más estrecha, entre el orden de los nacimientos y la mortalidad neonatal debida al nacimiento prematuro como causa fundamental o asociada (véase el cuadro 14).

Las tasas de mortalidad por nacimiento prematuro para el primer nacimiento variaron de 692.8 en California, hasta 1378.5 en Chile por cada 100000 nacidos vivos. Las tasas, en los mismos dos proyectos, para nacimientos de orden quinto y posterior fueron de 2024.7 y 2713.2

Representativos de los hallazgos que ligan la incidencia de enfermedades infecciosas con el tamaño de la familia, están los estudios de Din-

\section{Cuadro 14}

MORTALIDAD NEONATAL a DEBIDA A INMADUREZ COMO CAUSA SUBYACENTE O ASOCIADA, POR ORDEN DE NACIMIENTO, EN TRES PROYECTOS

\begin{tabular}{lccc}
\hline Orden de naoimlento & Chlle & $\begin{array}{c}\text { Merioo } \\
\text { Monterrey }\end{array}$ & $\begin{array}{c}\text { Estados Unidos } \\
\text { Callfornia }\end{array}$ \\
\hline Total & 1835.7 & 1320.5 & 990.2 \\
1 & 1378.5 & 1902.8 & 692.8 \\
2 & 1606.9 & 127.4 & 923.3 \\
3 & 1975.2 & 1153.2 & 143.8 \\
4 & 2423.1 & 1305.2 & 1802.7 \\
5 o mayor & 2713.2 & 1793.8 & 2024.7 \\
\hline
\end{tabular}

Fuente: Organización Panamericana de la Salud, "Patrones de mortalidad en la niñez", Publicación Científica, Núm. 262, 1973.

a Tasas por 100000 nacidos vivos. 
gle (1964) y sus asociados. Es clásico su estudio longitudinal con gran detalle sobre tamaño de la familia en Cleveland. Como ejemplo, las tasas de gastroenteritis infecciosa se encontraron directamente relacionadas con el tamaño de la familia. Los mismos investigadores encontraron relaciones similares entre la incidencia de enfermedades respiratorias infecciosas y el tamaño de la familia. Este estudio tomó en cuenta todo tipo de clases sociales.

La relación recién descrita entre mortalidad neonatal y edad de la madre y orden del nacimiento, demuestra la gran importancia de obtener, registrar, y utilizar información sobre edad de la madre y el orden de los nacimientos. Más aún, se ha encontrado que los niños de poco peso al nacimiento son más frecuentes entre madres jóvenes, lo que implica que también debe registrarse el peso al nacer para el análisis de la mortalidad general y específica. El conocimiento de estas relaciones sería de extrema utilidad como base para programas de desarrollo y evaluación en el campo de la salud materna e infantil [15].

En relación con los intervalos internatales, los espaciamientos ya sea muy cortos o muy largos, se ligan con mayores tasas de mortinatos, nacidos prematuros, y mortalidad neonatal y posneonatal $[18,20]$. Los resultados que se derivan de un estudio británico a nivel nacional (Douglas, 1950), y que incluyó más de 13000 nacimientos que ocurrieron en un período de una semana, mostraron que cuando el espaciamiento es mayor de dos años y menor de seis, es menor la posibilidad de tener un hijo de poco peso al nacer.

\section{El PAPEL DEL PEdiatra EN LA PLANEAción familiar}

Los pediatras y otros expertos en salud tienen muchas oportunidades de resumir los beneficios potenciales implícitos en una planeación familiar efectiva como parte integral de un plan de salud.

En programas de cuidados maternal e infantil, el estudio de las relaciones entre variables demográficas y salud, tal y como se ha discutido, provee información primordial para integrar la planeación familiar a los programas de salud.

Aunque el tamaño de la familia debe ser escogido libremente por los padres, hay factores importantes de tipo médico y biológico que deben tomarse en cuenta al aconsejar respecto a la planeación familiar. La esterilidad debe también tener prioridad en la investigación biológica de la reproducción humana. Por lo tanto, para el pediatra integrante de un centro de cuidado para la madre y el niño, la planeación familiar debe ser parte de un programa organizado de salud, no como prevención, sino para promover, proteger y recuperar la salud. Esta posición se definió en la 15a asamblea de la Organización Mudial de la Salud (1966).

Si esto es así, no hay necesidad de justificaciones económicas, sociales o demográficas para incluir la planeación familiar como una activi- 
dad en los programas de cuidado materno e infantil, ya que la causa de la pobreza y el subdesarrollo no radica en el tamaño de la familia. Los médicos y otros profesionistas de la salud son los.que más utilizan estos argumentos, aunque carezcan en general de conocimientos básicos de economía, ciencias sociales y demografía [19].

En América Latina, la población susceptible de riesgos respecto a salud maternal e infantil se encuentra grandemente en mujeres de edad fértil (alrededor de $21.3 \%$ ), y en niños menores de 15 años $(43 \%)$. Si se incluyeran los adolescentes hasta la edad de 19 años, entonces la población susceptible subiría hasta un $70 \%$ [16].

El propósito general de las unidades médicas es el de asegurar que la gente tenga suficiente supervisión profesional para gozar de buen consejo médico, de identificar a los que estén en peligro y de proporcionar la promoción, protección y rehabilitación de la salud, de acuerdo con las necesidades. "Por desgracia, para las multitudes que viven en países en desarrollo, los servicios médicos están muy lejos de llenar este propósito. La declaración de la Organización Mundial de la Salud sobre el derecho de cada individuo a la salud, ciertamente que suena vacía cuando se mira la diferencia entre las necesidades médicas y los servicios en la mayoría de los centros de rápida urbanización en América Latina, el Sudeste Asiático y África. La mayoría de los lectores de este artículo pertenecen a las clases privilegiadas, o relativamente privilegiadas, de la sociedad. En ellos, la mayoría de las enfermedades previsibles o tratables, han sido previstas o tratadas. Saben perfectamente, después de reflexionar deliberadamente, que tal salud, felicidad y comodidad depende de las condiciones sociales de sus hogares, más que de la proximidad de un hospital con una unidad de cobalto, o de un experto en trasplantes de órganos, o de una clínica de planeación familiar... Entre los no privilegiados, las unidades médicas son episodios lamentables. Puede que tengan acceso a unidades médicas de urgencia, pero los cuidados posteriores son a menudo inadecuados y los reingresos son frecuentes. Puede ser que tengan alguna supervisión en centros de salud, especialmente para inmunizaciones de rutina y dietas complementarias. Pero en todo el mundo, existe una gran proporción de gentes muy vulnerables que no tienen acceso a cuidados médicos ya sean preventivos, curativos, o de examen. Aún más, este mismo segmento se está reproduciendo a una tasa de casi el doble de la de los más privilegiados... En casi todos los países del mundo, a una alta tasa de natalidad se asocia un bajo estándar en el cuidado de la salud infantil. Es entonces razonable ver el porqué los planificadores toman el control de la población como panacea. Pero la pura reducción del tamaño de la población no mejora automáticamente las condiciones. Los Países Bajos son una de las áreas más densamente pobladas del mundo, pero no son ni insalubres, ni de baja educación, ni dependientes. Por otro lado, Arabia Saudita y Etiopía, con poblaciones dispersas, están notablemente atrasados al igual que Brasil y muchos países latinoamericanos." "La educación y los servicios de planeación fami- 
liar son sin duda alguna componentes de un programa de salud, aunque sobreenfatizar tales componentes a costa de las necesidades de nutrición y de cuidados maternos e infantiles en la familia puede no producir mayores estándares en el nivel de vida, la educación, y la responsabilidad [2].

En conclusión, reconocemos que la planeación familiar debe formar parte de los programas de protección de la salud materna e infantil, equilibrando los recursos que a este propósito se asignen con el resto de las necesidades de salud. La implementación de estos servicios debe hacerse en circunstancias que permitan garantizar la libertad en su utilización. Esto implica que se eduque y se dé información digna de confianza, y se proporcione un sistema de justa distribución al igual que un mayor nivel de vida, junto con los derechos humanos que garanticen la capacidad de educar y procrear el número de hijos que cada familia desea [9].

\section{REFERENCIAS BIBLIOGRÁFICAS}

1. Boletim Informativo da BEMFAM, Sociedade Civil de Bem Estar Familiar no Brasil, Rio de Janeiro, 6, octubre-diciembre de 1972.

2. L. J., Gasazza y C. D. Williams, "Family Health Versus Family Planning", Lancet 1, pp. 712-14, 1973.

3. R. V. da Costa, "EI crecimiento de la población y el desarrollo económico. El caso brasileño", Boletín de Población, Bogotá, 2 (3), pp. 3-31, mayo de 1970.

4. R. Delgado García, "Latin America", en B. Berelson (Comp.), Family Planning and Population Programs: A Review of World Developments, Chicago, University of Chicago Press, 1966, pp. 249-257.

5. J. H., Dingle, et al. apud E. Siegel, "Preventive Pediatrics: The Potential of Family Planning", Journal of Medical Education, 44 (11, parte 2), pp. 74-80, noviembre de 1969.

6. J. W. B. Douglas, apud E. Siegel, "Preventive Pediatrics: The Potential of Family Planning", Journal of Medical Education, 44 (11, parte 2), pp. 74-80, noviembre de 1969.

7. A. Fucaraccio, "El control de la natalidad y el argumento del ahorro y la inversión", en Conferencia de Escuelas de Salud Pública de América Latina Sobre Salud y Población, Santiago, 1970, Washington, OPAS, 1971, pp. 90-100 (Publicación Científica, 232).

8. M. L. García, "Programas de planificación familiar en América Latina, 1969", en Actas I, Conferencia Regional Latinoamericana de población, México, 1970, El Colegio de México, 1972, pp. 393-400.

9. Informe Final, Conferencia de Escuelas de Salud Pública de América Latina sobre Salud y Población, Santiago, 1970, Washington, OPAS, 1971, pp. 7-16 (Publicación Científica, 232).

10. J. Menken, "The Health and Social Consequences of Teenage Childbearing", Family Planning Perspectives, 4 (3), pp. 45-54, julio de 1972.

11. C. A. Miró, "Aspectos demográficos de América Latina", en Population Reference Bureau, Programas Internacionales de Población - Población y desarrollo, Bogotá, 1970, pp. 7-12.

12. D. Nortman, Population and Family Planning Programs: A Factbook Reports on Population Family Planning, Nueva York (2, 4a edición), septiembre de 1972.

13. Population Reference Bureau, "Extrema esquerda e o problema de Popula- 
çao: aceitada planificaçao familiar e rechacado control de natalidade como soluçao ao subdesenvolvimiento latinoamericano", Washington, D. C. Bogotá, Colombia, 1969 (comunicado de prensa).

14. Population Reference Bureau, "El subdesarrollo general, más que influencia católica, responsable por altas tasas de natalidad en América Latina", Población y Desarrollo, Bogotá, 1970, pp. 105-112.

15. R. R. Puffer y C. V. Serrano, "Patterns of Mortality in Childhood: Report of the Inter-american Investigation of Mortality in Childhood", Washington, Organización Panamericana de la Salud, 1973, pp. 241-256.

16. J. Rosselot, Salud maternoinfantil en Latinoamérica, Boletín Oficial Sanitario Panamericano, 70 (5), pp. 407-421, 1971.

17. V. L. Urquidi, "O desenvolvimento economico e o aumento de populaçao", Washington, D. C., Bogotá, Colombia, Population Reference Bureau (Programas Internacionais de Populaçao).

18. J. Wray, apud J. Menken, "The Health and Social Consequences of Teenage Childbearing", Family Planning Perspectives, 4 (3), pp. 45-53, julio de 1972.

19. J. Yunes, "A Dinamica populacional dos paises desenvolvidos e subdesenvolvidos", Revista de Saude Publica, São Paulo, 5, pp. 129-50, 1971.

20. J. Yunes, "Relationships of Parity, Spacing, and Outcome of Previous Pregnacies with Maternal and Infant Mortality and Morbidity: A Review", Ann Arbor, 1967, 15 fls (mimeografiado). 